\title{
Phenol/formaldehyde-derived macroporous carbon foams prepared with aprotic ionic liquid as liquid template
}

\author{
Haebong Byun ${ }^{1}$, Gimin Nam ${ }^{1}$, Young-Mok Rhym ${ }^{2}$ and Sang Eun Shim ${ }^{1, \star}$ \\ ${ }^{1}$ Department of Chemical Engineering, Inha University, Incheon 402-751, Korea \\ ${ }^{2}$ Korea Institute of Materials Science, Changwon, 641-841, Korea
}

\section{Article Info \\ Received 3 January 2012 \\ Accepted 29 March 2012 \\ *Corresponding Author \\ E-mail: seshim@inha.ac.kr \\ Tel: $+82-32-860-7475$}

\section{Open Access}

DOI: http://dx.doi.org/ 10.5714/CL.2012.13.2.094

This is an Open Access article distributed under the terms of the Creative Commons Attribution Non-Commercial License (http://creativecommons.org/licenses/ by-nc/3.0/) which permits unrestricted non-commercial use, distribution, and reproduction in any medium, provided the original work is properly cited.

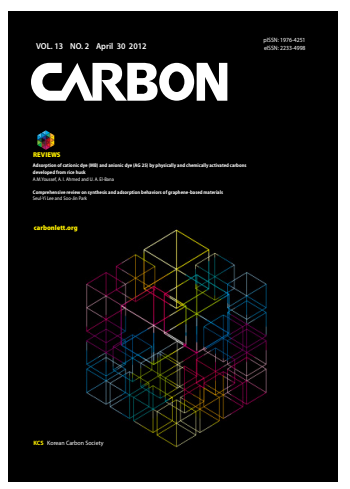

http://carbonlett.org

pISSN: 1976-4251

eISSN: 2233-4998

Copyright $\odot$ Korean Carbon Society

\begin{abstract}
Herein, macroporous carbon foams were successfully prepared with phenol and formaldehyde as carbon precursors and an ionic liquid, 1-butyl-3-methylimidazolium hexafluorophosphate $\left(\mathrm{BMIPF}_{6}\right)$, as a pore generator by employing a polymerization-induced phase separation method. During the polycondensation reaction of phenol and formaldehyde, $\mathrm{BMIPF}_{6}$ forms a clustered structure which in turn yields macropores upon carbonization. The morphology, pore structure, electrical conductivity of carbon foams were investigated in terms of the amount of the ionic liquid. The as-prepared macroporous carbon foams had around 100-150 $\mu \mathrm{m}$-sized pores. More importantly, the electrical conductivity of the carbon foams was linearly improved by the addition of BMIPF $_{6}$. To the best of the author's knowledge, this is the first result reporting the possibility of the use of an ionic liquid to prepare porous carbon materials.
\end{abstract}

Key words: carbon foam, phenolic resin, ionic liquid, pore, electrical conductivity

\section{Introduction}

During the last two decades, interest in the preparation and utilization of carbon foams has been rapidly growing due to their advantageous properties. Carbon foams have been used as catalyst electrodes, supports, tunable thermal insulations, high temperature applications, lightweight structural parts, radar absorption materials, filters for molten metals and corrosive chemicals, etc. [1,2].

Recently, a less time-consuming process for fabricating carbon foams using organic polymers has been developed. Representative examples of polymeric materials which can be used as precursors for glassy carbon foams are phenol-formaldehyde, resorcinol-formaldehyde, phloroglucinol-formaldehyde, polyvinylidene chloride, polyacrylonitrile, furfural resin, and their blends [3]. In order to produce carbon foams using polymeric precursors, the use of a sacrificial template is an efficient approach to generate pre-determined pore sizes. The sacrificial templates are impregnated or filled into carbon precursors. After the carbonization and in-situ or subsequent template removal, macroporous carbon monoliths can be easily obtained.

As an alternative method, the polymerization-induced phase separation principle has been utilized to synthesize porous carbon monoliths. An initial homogeneous solution of reactive monomers as the carbon precursor, and non-reactive components (NRCs), undergo phase separation in the course of polymerization, to give a co-continuous morphology. In this process, ethyl glycol derivatives or polyethylene glycol have been mainly used as NRCs [4].

Room temperature ionic liquids (RTILs) are unique solvents that contain an organic cation and an inorganic anion in the liquid state at ambient condition. RTILs such as imidazolium, pyridinium, and ammonium salts have a high ionic mobility and ion concentration. In addition, RTILs have negligible vapour pressure, high thermal stability, and excellent electrical 
conductivity $[5,6]$. In this article, macroporous carbon foams were prepared using phenol-formaldehyde $(\mathrm{PF})$ as a carbon precursor and alcohol-soluble ionic liquid, 1-butyl-3-methylimidazolium hexafluorophosphate $\left(\mathrm{BMIPF}_{6}\right)$, as pore generator. The effect of the $\mathrm{BMIPF}_{6}$ on the properties of carbon foams was investigated.

\section{Experimental}

\subsection{Raw materials}

Phenol (99+ \%) was purchased from Sigma-Aldrich (USA). $\mathrm{BMIMPF}_{6}$ was obtained from C-tri (Korea). $\mathrm{NaOH}$ as a catalyst, formaldehyde (37\% aqueous solution), and ethanol were supplied by Duksan Chemicals (Korea).

\subsection{Preparation of macroporous carbon foams}

Precursors for carbon foam were synthesized by a typical condensation polymerization technique. $3.24 \mathrm{~g}$ phenol was poured in $50 \mathrm{~mL}$ beaker. 0.9/1.8/3.6 $\mathrm{g} \mathrm{BMIPF}_{6}(10 / 20 / 40 \mathrm{wt} \%$ to $9 \mathrm{~g}$ ethanol, respectively) and $0.45 \mathrm{~g} \mathrm{NaOH}$ were dissolved thoroughly in $0.45 \mathrm{~g}$ alcohol. Temperature was elevated to $50^{\circ} \mathrm{C}$. Four point three seven gram formaldehyde (the molar ratio of $\mathrm{P} / \mathrm{F}$ : 1.6) was injected into the beaker and polymerization was continued at $300 \mathrm{rpm}$ for $6 \mathrm{~h}$. Then temperature was elevated to $70^{\circ} \mathrm{C}$ and the polymerization proceeded for an additional 36 $\mathrm{h}$. The cured body was pyrolyzed stepwise in order to prevent cracks on the surface: (1) ramping the temperature up to $120^{\circ} \mathrm{C}$ with a heating rate of $2^{\circ} \mathrm{C} / \mathrm{min}$ and holding for $2 \mathrm{~h}$, (2) raising to $600^{\circ} \mathrm{C}$ and holding for $2 \mathrm{~h},(3)$ increasing to $800^{\circ} \mathrm{C}$ with holding for $2 \mathrm{~h}$. Then it was cooled down to room temperature. Fig. 1 shows the procedure for the preparation of the carbon foams.

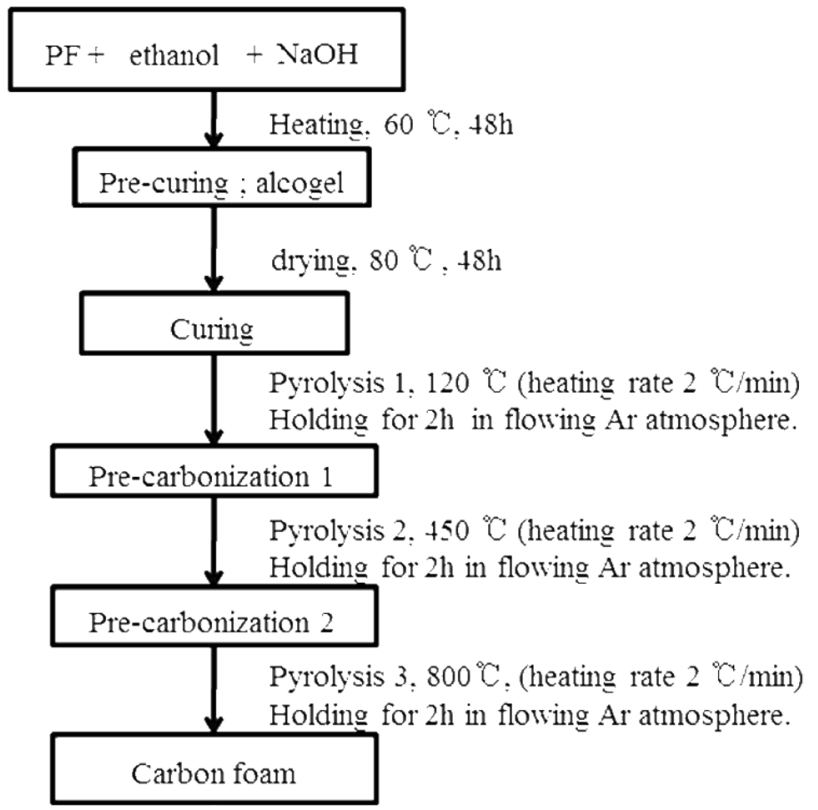

Fig. 1. Flowchart for the preparation of carbon foams using phenolic resin and ionic liquid.
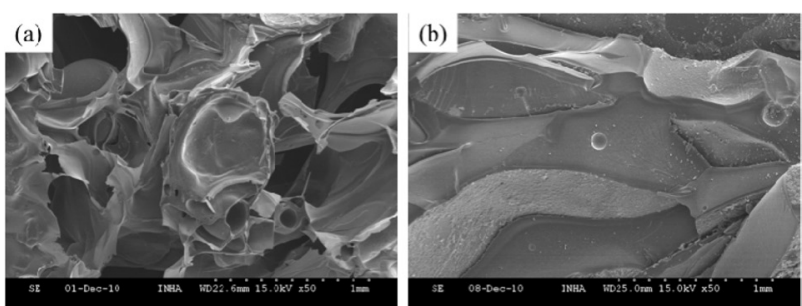

Fig. 2. Scanning electron microscope microphotographs of carbon foam prepared by phenol/formaldehyde molar ratio of (a) 1.6 and (b) 3.2 .

\subsection{Characterization}

Scanning electron microscope (SEM) micrographs were obtained by Hitachi S-4300. The samples were coated with platinum before characterization. Thermogravimetric analysis (TGA) was carried out using a Diamond TG/DTA Lab System (Perkin Elmer) with the heating rate of $10^{\circ} \mathrm{C} / \mathrm{min}$. The structural properties of the carbon foams were determined by XRD (D/ MAX 2200V/PC, Rigaku, Japan) using a diffractometer with $\mathrm{Cu}$ $\mathrm{K} \alpha$ radiation over the $2 \theta$ range of $20-100^{\circ}$. The electrical conductivity was examined by MCP-T610 (Mitsubishi Chemical Corporation, Japan). The apparent density $\left(\rho_{\text {app }}\right)$, pore size distribution and porosity ( $\square$ ) of the carbon foams were examined by mercury porosimetry (Micromeritics Poresizer 9320). Skeletal density $\left(\rho_{\mathrm{s}}\right)$ was calculated based on $\mathrm{L}$ :

$$
\rho_{\mathrm{s}}=\frac{\rho_{\mathrm{app}}}{\left(1-\frac{\square}{100}\right)}
$$

and total volume was calculated based on [7]:

$$
\mathrm{V}_{\mathrm{t}}=\frac{1}{\rho_{\mathrm{app}}}-\frac{1}{\rho_{\mathrm{s}}}
$$

\section{Results and Discussion}

It is noted that the molar ratio of phenol $(\mathrm{P})$ to formaldehyde (F) affects the resulting pore structure and pore size of the prepared porous carbon materials. A P/F molar ratio of 0.8 is a very general synthesis ratio [8]. It has been known that an $0.8 \mathrm{P} / \mathrm{F}$ molar ratio produces mesopore and micropore structures. Since we aimed to prepare macroporous carbon foams, a different $\mathrm{P} / \mathrm{F}$ molar ratio was needed. Figs. $2 \mathrm{a}$ and $\mathrm{b}$ show the structure of carbon foams using 1.6 and $3.2 \mathrm{P} / \mathrm{F}$ molar ratio. It is seen that a macroporous carbon foam structure containing plenty of pores and thin junk area was well-developed for the $1.6 \mathrm{P} / \mathrm{F}$ molar ratio, however, the $3.2 \mathrm{P} / \mathrm{F}$ molar ratio did not yield a porous structure. It means that the $\mathrm{P} / \mathrm{F}$ molar ratio is an important factor to generate the desired porous structure. Therefore, 1.6 P/F molar ratio was a suitable condition for fabricating the macroporous carbon materials aimed in this study.

Fig. 3 shows the morphology of the resulting carbon foams prepared by $1.6 \mathrm{P} / \mathrm{F}$ molar ratio using different amounts of $\mathrm{BMIPF}_{6}$. All fabricated carbon foams have macroporous structures by the incorporation of $\mathrm{BMIPF}_{6}$ after carbonization. Fig. $3 \mathrm{~b}-\mathrm{d}$ reveal that junk areas and pore sizes are decreased with 

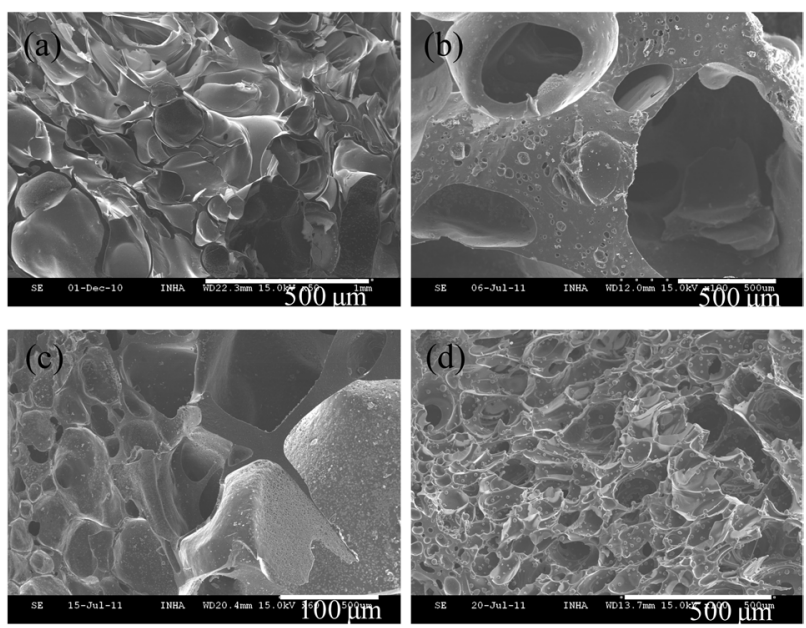

Fig. 3. Scanning electron microscope microphotographs of carbon foams prepared by PF resin with different amounts of BMIPF 6 : (a) 0, (b) 20, (c) 30 , and (d) $40 \mathrm{wt} \%$.

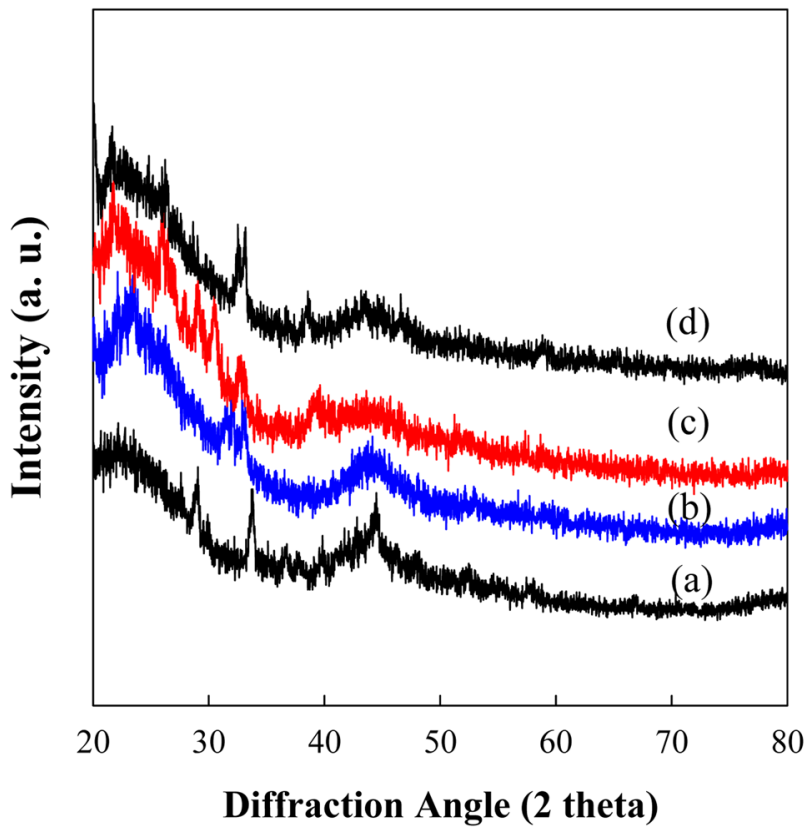

Fig. 4. X-ray diffraction patterns of the carbon foams prepared by phenol-formaldehyde resin with different amounts of BMIPF 6 : (a) 0, (b) 20, (c) 30 , and (d) $40 \mathrm{wt} \%$.

the increase in the amount of BMIPF $_{6}$ in carbon foams. To the best of our knowledge, this is the first report suggesting that ionic liquids can be used as a liquid type pore generator in the fabrication of carbon foams. Fig. 4 represents X-ray diffraction (XRD) patterns of the carbon foams derived from PF resin and BMIPF $_{6}$. Two broad peaks of the carbon foams could be seen at $2 \theta=23$ and $43^{\circ}$ originating from the (002) plane of porous carbons. The (002) plane is a diffusive type and the corresponding interplaner d-spacing is $4.09 \AA$ which is far higher than that of graphite. According to XRD patterns, it can be deduced that the resulting carbon foams were partially crystalline, but had more amorphous portion than graphite.

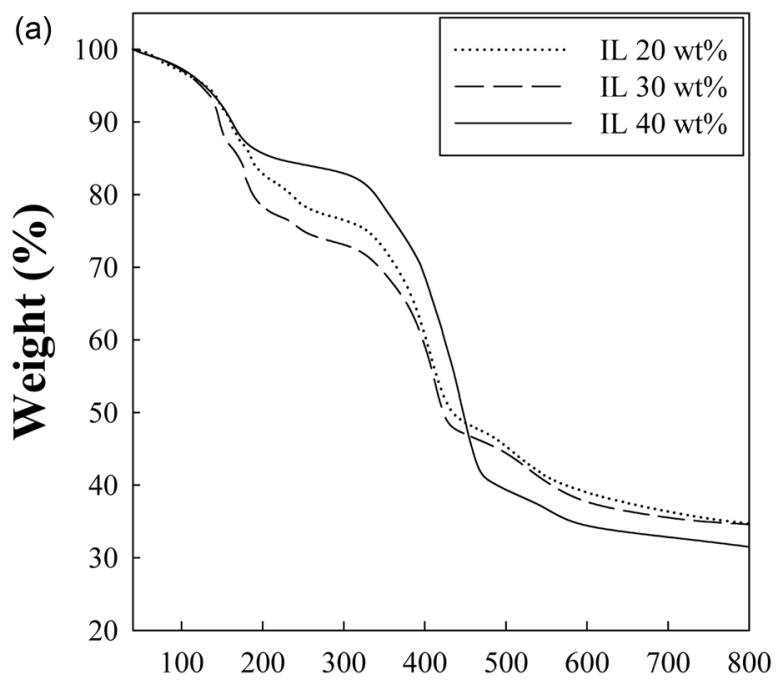

Temperature $\left({ }^{\circ} \mathrm{C}\right)$

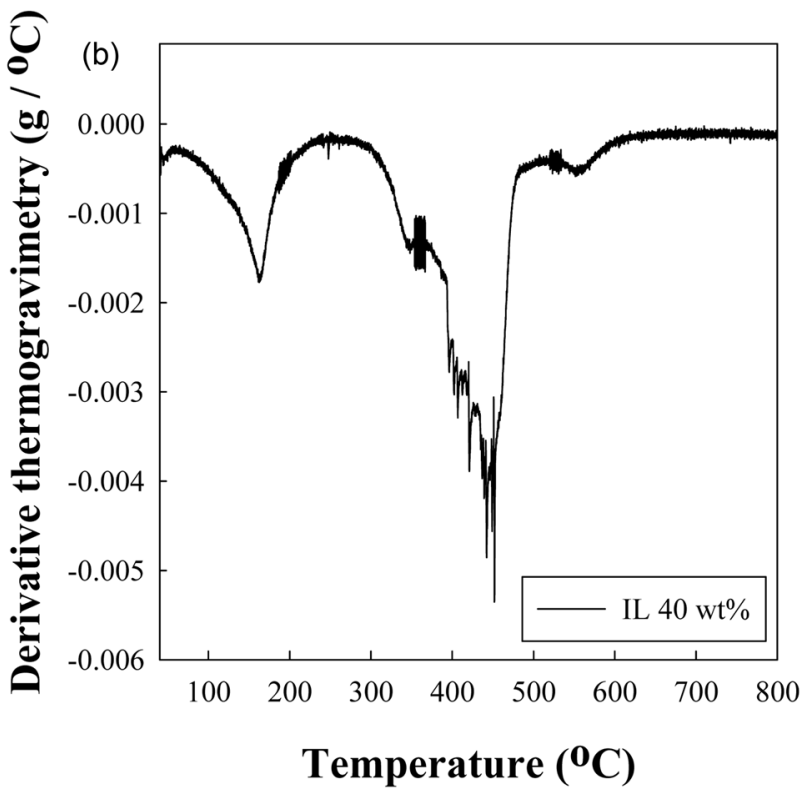

Fig. 5. (a) Thermogravimetric analysis of a phenol-formaldehyde cured body containing $40 \mathrm{wt} \% \mathrm{BMIPF}_{6}$, and (b) its derivative plot.

Fig. 5 shows the weight loss of cured PF body containing different amounts of ionic liquid upon heating. As shown in Fig. $5 \mathrm{a}, 68,66.5 \%$ weight loss of cured resole resins is caused by the removal of unreacted materials, $\mathrm{BMIPF}_{6}$, and by-products in the cured resin [9]. Fig. 5b indicates the derivative plot of weight loss of cured body containing $40 \mathrm{wt} \% \mathrm{BMIPF}_{6}$. The specific reaction temperature ranges were observed around 340,450 , and $530^{\circ} \mathrm{C}$, where further cross-linking and polycondensation, and carbonization reaction mainly occurred, respectively.

Table 1 summarizes the density and structure of pores of carbon foams prepared using different amounts of $\mathrm{BMIPF}_{6}$ as a pore generator. The porosity and total volume of carbon foams are on the order of 40, 20 and $30 \mathrm{wt} \% \mathrm{BMIPF}_{6}$, meanwhile bulk density is in the order of 20,30 , and $40 \mathrm{wt} \%$. The porosity and apparent density 
Table 1. Properties of the carbon foams prepared with $\mathrm{PF}$ resin and $\mathrm{BMIPF}_{6}$

\begin{tabular}{ccccccc}
$\begin{array}{c}\mathrm{BMIPF}_{6} \\
(\mathrm{wt} \%)\end{array}$ & $\begin{array}{c}\text { Porosity } \\
(\%)\end{array}$ & $\begin{array}{c}\text { Bulk density } \\
\left(\mathrm{g} / \mathrm{cm}^{3}\right)\end{array}$ & $\begin{array}{c}\text { Apparent density } \\
\left(\mathrm{g} / \mathrm{cm}^{3}\right)\end{array}$ & $\begin{array}{c}\text { Skeletal density } \\
\left(\mathrm{g} / \mathrm{cm}^{3}\right)\end{array}$ & $\begin{array}{c}\text { Total pore volume } \\
(\%)\end{array}$ \\
\hline 0 & 40.32 & 0.77 & 1.45 & 2.43 & 0.278 \\
\hline 20 & 45.02 & 0.79 & 1.48 & 2.69 & 3.16 & 0.304 \\
\hline 30 & 51.23 & 0.84 & 1.54 & 1.61 & 0.253 \\
\hline 40 & 41.52 & 0.87 & & 2.75 & 0.257 \\
\hline
\end{tabular}

PF: phenol-formaldehyde.

Table 2. Electrical conductivity of the carbon foams prepared by $P F$ with BMIPF$_{6}$

\begin{tabular}{cc}
$\mathrm{BMIPF}_{6}(\mathrm{wt} \%)$ & Electrical conductivity $(\mathrm{S} / \mathrm{cm})$ \\
\hline 10 & 3.904 \\
\hline 20 & 4.152 \\
\hline 30 & 4.278 \\
\hline 40 & 4.425 \\
\hline
\end{tabular}

PF: phenol-formaldehyde.

increase from $45.02 \%$ and $1.48 \mathrm{~g} / \mathrm{cm}^{3}$ to $51.23 \%$ and $1.54 \mathrm{~g} / \mathrm{cm}^{3}$, respectively. But the carbon foam prepared by $40 \mathrm{wt} \% \mathrm{BMIPF}_{6}$ has $41.52 \%$ and $1.61 \mathrm{~g} / \mathrm{cm}^{3}$ of porosity and apparent density, respectively. During the pyrolysis, the condensation reaction released water in cured resole resin foam [10]. It is thought that the carbon foam structure is also formed by interconnection between $\mathrm{PF}$ and $\mathrm{BMIPF}_{6}$ during hydrothermal treatment. $\mathrm{BMIPF}_{6}$ dissolves in ethanol and water. It is assumed that $\mathrm{BMIPF}_{6}$ has a clustering behavior and water molecules are released upon heating the PF cured body, which causes the change in porosity and total pore volume. But, the carbon foam prepared by $40 \mathrm{wt} \%$ BMIPF 6 has low porosity and total volume since the saturation of $\mathrm{BMIPF}_{6}$ disturbed its dispersion in PF resin.

Table 2 lists the electrical conductivity of carbon foams prepared using different amounts of $\mathrm{BMIPF}_{6}$. Interestingly, the electrical conductivity linearly increased from 3.904 to 4.425 $\mathrm{S} / \mathrm{cm}$ with the increased amount of $\mathrm{BMIPF}_{6}$. The reason for the enhanced electrical conductivity can be found from the bulk density. Also, the ionically conductive $\mathrm{BMIPF}_{6}$ fragment may improve the electrical conductivity even after carbonization. Finally, we found that ionic liquids can be used to prepare macroporous carbon foams and the electrical conductivity could be improved by the incorporation of ionic liquids.

\section{Conclusions}

This paper presents a novel preparation method of macroporus carbon material using phenol/formaldehyde with an ionic liquid, $\mathrm{BMIPF}_{6}$ as a liquid type pore generator. In order to prepare macroporous carbon foam, the molar ratio of $\mathrm{P} / \mathrm{F}$ was decided to be 1.6. By addition of $\mathrm{BMIPF}_{6}$, a well-developed macroporous structure was obtained in the range of $10-40 \mathrm{wt} \%$ of $\mathrm{BMIPF}_{6}$. The porous structure was developed by the phase separation between $\mathrm{PF}$ resin and $\mathrm{BMIPF}_{6}$ during polycondensation reaction. $\mathrm{XRD}$ analysis reveals that amorphous-rich carbon materials with a small crystalline portion were successfully fabricated. It was seen that various aspects of the porous carbon such as porosity, bulk density, apparent density, total volume, and morphology were controllable by changing the amount of $\mathrm{BMIPF}_{6}$. Up to the $30 \mathrm{wt} \% \mathrm{BMIPF}_{6}$, the carbon foams had higher porosity and total pore volume. Interestingly, the electrical conductivity of the carbon foams was progressively enhanced with the amount of $\mathrm{BMIPF}_{6}$ due to greater bulk density and the residual $\mathrm{BMIPF}_{6}$ fragment after carbonization.

\section{Acknowledgements}

This work was supported by a grant (M2009010020) from the Fundamental R\&D Program for Core Technology of Materials funded by the Ministry of Knowledge Economy (MKE), Republic of Korea.

\section{References}

[1] Zhang L, Ma J. Processing and characterization of syntactic carbon foams containing hollow carbon microspheres. Carbon, 47, 1451 (2009). http://dx.doi.org/10.1016/j.carbon.2009.01.037.

[2] Kosonen H, Valkama S, Nykanen A, Toivanen M, ten Brinke G, Ruokolainen J, Ikkala O. Functional porous structures based on the pyrolysis of cured templates of block copolymer and phenolic resin. Adv Mater, 18, 201 (2006). http://dx.doi.org/10.1002/ adma.200401110.

[3] Prabhakaran K, Singh P, Gokhale N, Sharma S. Processing of sucrose to low density carbon foams. J Mater Sci, 42, 3894 (2007). http://dx.doi.org/10.1007/s10853-006-0481-1.

[4] Lafyatis DS, Tung J, Foley HC. Poly(furfuryl alcohol)-derived carbon molecular sieves: dependence of adsorptive properties on carbonization temperature, time, and poly(ethylene glycol) additives. Ind Eng Chem Res, 30, 865 (1991). http://dx.doi.org/10.1021/ ie $00053 \mathrm{a} 008$.

[5] Lu X, Zhou J, Zhao Y, Qiu Y, Li J. Room temperature ionic liquid based polystyrene nanofibers with superhydrophobicity and conductivity produced by electrospinning. Chem Mater, 20, 3420 (2008). http://dx.doi.org/10.1021/cm800045h.

[6] Jacob DS, Rothschild A, Tuller HL, Gedanken A. In situ sonochemical hydrolysis and deposition of composite layers of ionic liquid entrapped in colloidal silica network and their application as sensors for various gases. Ultrason Sonochem, 17, 726 (2010). 
http://dx.doi.org/10.1016/j.ultsonch.2009.12.015.

[7] Lu Y, Li Z, Wang P, Yang C. Preparation of mesophase pitch-based carbon foams with supercritical toluene. J Appl Polym Sci, 121, 336 (2011). http://dx.doi.org/10.1002/app.33607.

[8] Meister JJ. Polymer Modification: Principles, Techniques, and Applications, Marcel Dekker, New York, 575-705 (2000).
[9] Morterra C, Low MJD. I.R. studies of carbons - VII. The pyrolysis of a phenol-formaldehyde resin. Carbon, 23, 525 (1985). http:// dx.doi.org/10.1016/0008-6223(85)90088-0.

[10] Jackson WM, Conley RT. High temperature oxidative degradation of phenol-formaldehyde polycondensates. J Appl Polym Sci, 8, 2163 (1964). http://dx.doi.org/10.1002/app.1964.070080516. 